\title{
SUPPORTING THE CREATION OF VIRTUAL ENTERPRISES USING MOBILE AGENTS
}

\author{
Silvia Simões-Costa, Ricardo J. Rabelo \\ Federal University of Santa Catarina, Department of Automation and Systems, BRAZIL, \\ silvia@das.ufsc.br, rabelo@das.ufsc.br
}

\begin{abstract}
In this paper we present a semi-automated process of brokerage for a cluster of mould and die industries located in the south of Brazil, called TECHMOLDES. This process is represented by a multi-agent-based decision support system that helps a human-broker in the selection of the group of enterprises within TECHMOLDES which better fits a given business opportunity. This work applies mobile agents to treat information about the cluster. The agents visits each enterprise that are capable of participating in the business, takes the bids from each one, and utilizes this information to generate a set of possible Virtual Enterprises for each business opportunity.
\end{abstract}

\section{INTRODUCTION}

The need to increase the competitiveness, the fast change of the consumers needs and the arising of new manufacturing and information technologies have brought about great changes in the production style and in the configuration of manufacturing enterprises. TECHMOLDES is a virtual organization (VO) composed of nine mould and die SMEs located in the south of Brazil. It was created as a strategic solution to face the current market needs that demand smaller delivery times and, consequently, larger productive capacity. Acting like a VO, the enterprises are seen by the final customer as a unique productive entity, consequence of the combination of the individual skills of each enterprise-member, although remaining "transparent" to the customer. Therefore, they can increase their chances in the global market. Each business opportunity that is submitted to TECHMOLDES is evaluated in order to grab the possible "coalitions" of enterprises that can carry it out. In this work, each one of these coalitions is seen as a virtual enterprise (VE). A VE is a temporary alliance of enterprises that come together to share skills and resources in order to better respond to business opportunities, and whose cooperation is supported by computer networks (Camarinha-Matos et al., 99).

The formation of VEs includes two fundamental issues in order to reach the desired competitiveness: the agility in the introduction of the new business to the TECHMOLDES enterprises, and the efficiency in the creation and analysis of the possible VEs. At this stage, the role of the broker ("negotiator") is very important. The broker is the entity that coordinates the brokerage process: the search of business opportunities for the cluster of enterprises it represents, and the selection of which enterprises (a VE) should indeed participate on this business. 
This work exploits the complexity of this selection, presenting a decision-support system based on mobile agents for that. It acts in the creation phase of the VE life cycle, representing an evolution of the work introduced in (Rabelo et al., 97), and offering another alternative for the approach of (Rabelo et al., 01).

The paper is organized as follows: Section 2 describes the scenario of TECHMOLDES operation. Section 3 presents the concept of "brokerage" in this context. Section 4 details the operation of TECHMOLDES as a decision support system to brokerage based on mobile agents. Section 5 discusses the mobile agents' technology. Section 6 comments on the architecture of the prototype being developed. Section 7 focuses on the aspects of the prototype implementation. Finally, Section 8 presents some conclusions and the next steps to be carried out.

\section{THE TECHMOLDES CLUSTER}

In the moulds and die industry, the customer usually decides to purchase a mould or die considering three main factors: quality, cost, and delivery time. However, another factor is emerging in importance, which is the agility in the negotiation process. In the traditional process, without the presence of a "coordinator", and with enterprises "randomly" organized, decision making becomes complicated. This slows the process through which enterprises decide which of them are going to work in that business. The strategic solution proposed in this work, that aims to improve the agility in the VE formation, uses a support system and a human negotiator. This negotiatior coordinates the process since the reception of the customers' requests until the selection of the most suitable consortium of enterprises to a specific business.

Before the broker can reply to the customer once a business is arrived, two problems rise up. The first one concerns to the complexity in providing a reliable answer to the customer. There are usually dozens of possibilities of VEs that have the requirements for a certain business, and the task to analyze the quality of each one is difficult and time consuming. The central point is that the primordial function of the broker should be to look for new business opportunities instead. Therefore, a system that aids the broker in that task is extremely important, since a non-assisted scheduling done by the human broker can lead to a less lucrative VE in terms of final cost, and even to the loss of the business.

The second problem is related to the agility in providing a reliable answer to the customer. Considering the problem previously addressed, the broker should have a support system that aids him in the global process: the announcement of the opportunity, the gathering of proposals from each enterprise, the selection of the best possibility, and finally the answer to the customer.

\section{THE BROKERAGE APPROACH}

The broker is a human specialist who represents TECHMOLDES and who plays two main roles: looking for new business opportunities and to manage their reception, and coordinating the process of selecting the most suitable consortium of enterprises for every opportunity. In order to improve the agility in the business management, 
this work proposes a decision support system for the broker. Thus, by means of a broker agent, an acquired business opportunity - a group (or "package") of moulds of a certain customer - is transformed into a distributed business process (DBP) which in turn is split into business processes (BPs), where each BP corresponds to an individual mould. The individual mould tenders are then distributed among the enterprises, and further the most adequate coalition should be then elected. Depending on the business requirements and the available capacities and skills, it may happen that various alternatives of teams of enterprises ("internal" VEs) that can accomplish the various BPs may be found. Figure 1 illustrates the idea of having three possible VEs within the cluster to attend a given DBP (for ease of understanding only VE2 has BPs explicitly assigned to the enterprises " $E$ ", and with the consequent material/information flow among them).

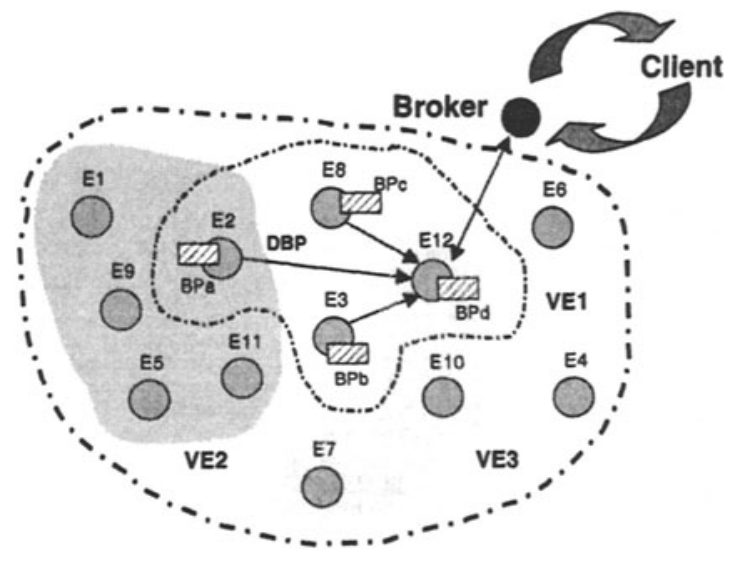

Figure 1 - A VE Scenario within TECHMOLDES

This work presents a multi-agent-based decision support system - called MobiC that aims (i) to assist the human broker in decision-making process of selection of the most adequate consortium of enterprises for a given package, and (ii) serving as a supporting tool for the optimization of the package's schedules regarding the information that comes from the PPC systems of each enterprise. As the cluster members are potential competitors, the final decision is taken by a management board, coordinated by the broker. The final decision is based on the criteria of $V E$ (package) lowest cost and lowest delivery date.

\section{THE TECHMOLDES SCENARIO}

Today the enterprises receive a client order both directly (in a traditional way) and through the broker, and it can contain an individual or a set of moulds and/or dies (a "package"). Such order specifies the mould size (in tons), its type (mould or die), the part material (aluminum or plastic), and the delivery date (for each mould of the entire package). For the broker, each enterprise of the cluster is seen in terms of its capacities, represented through the type and the size of the mould/die that it is capable to manufacture. Figure 2 stresses the six basic steps of MobiC system: 
1) For each business opportunity, the broker analyzes the package (DBP) and identifies who are potential enterprises for each mould or die (BP), and distributes the client order among the enterprises.

2) The involved enterprises receive, analyze and answer/bid with a simple "ok" if they are interested and available to satisfy technical and temporal requirements.

3) A mobile agent (MAg) is sent to the bidders and it establishes a dialogue with each Enterprise-Agent (EA). The MAg asks the EA for data of the enterprise local BD (capacity and delivery time) and, interacts with the enterprise supervisor, asking about price, and waits for a confirmation or eventual adjustment of delivery date that comes from de PPC.

4) The MAg moves through all the remaining enterprises, keeping the data from all the enterprises visited before. Finally, the MAg returns to the broker with the possible VEs alternatives (and their scheduling), also providing some indicators.

5) The broker chooses the most appropriate VE with the management board.

6) The broker agent sends a message for the elected enterprises, notifying them about the final result that corresponds to the final agreement for the business.

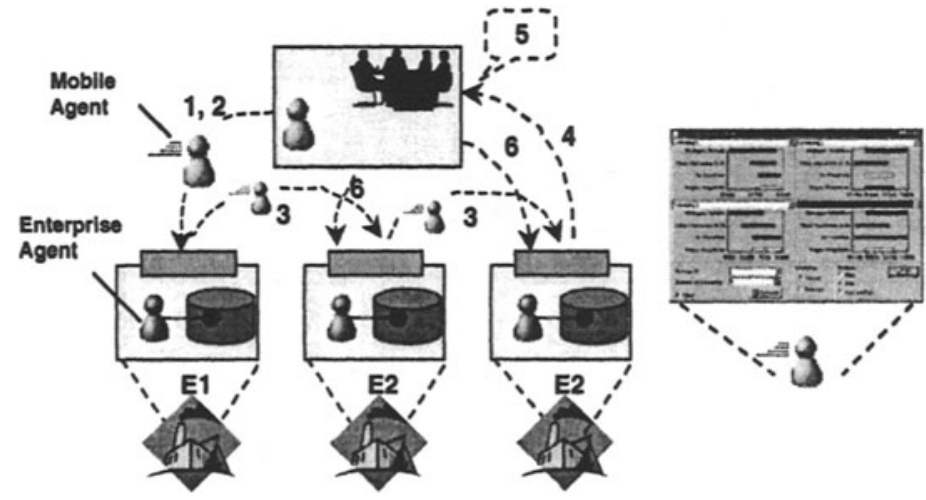

Figure 2 - The MobiC approach

For the following discussion, one considers a scenario where:

- a client order arrives via the broker and as a package;

- for each mould within a package, an enterprise cannot subcontrat another enterprise, either for the entire mould or to contrat some hours in a machine for the execution of a certain mould's operation;

- a client order is complete (all information is completely and precisely specified) and definitively set when it goes to the broker.

\section{THE MOBILE AGENTS}

There are several possible implementation approaches for this type of decision support system. Considering the characteristics of the problem and the current scenario, the multi-agent systems represent an adequate approach to model it. In this work, agents are software modules distributed in the network with specific abilities 
with the capacity to interact with other agents, to apprehend the environment, presenting some degree of autonomy for decisions.

The most common multi-agent systems are those that use the stationary agents paradigm that implement the agents as static programs. This means that once they have been executed in a computer, they do not have abilities and autonomy to move to another computer. However, compared with the stationary approach, the mobile agents approach, intrinsic problems associated to the usual enormous traffic in the net are revealed as a consequence of several inter-agent interactions. These are potentially expensive, affect the system performance directly, and any fault in the net can threaten a coherent global final result (Szirbic et al., 1999).

A MAg can be defined as an agent capable of migrating from one place to another on the net and (re)start or continue its execution from that point on. The migration consists of transferring the code and the agent execution state. Nowadays MAg have been applied on several areas, such as on VE (Brugali et al., 1999), (Papaiannou et al., 1999), (Szirbik et al., 1999). Some other works such as (Rocha et al., 99) have persued a MAS-driven automated brokarage based on hypothetical scenarios. Manual or strongly human-assisted brokarage based on real industrial cases having more complex competencies descriptions and relationships are proposed in (Bremer et al., 99) an (Molina et al., 98).

In the context of TECHMOLDES, the MAg technology presents several important features not only for the supporting of current needs, but also for innovations that are planned for the future. MAg support dynamic reconfiguration of their "missions", automatic versions updating, lower dependence from the network, remote (re)installation and dynamic addition of new functionalities in remote computers. Besides, they can adaptability themselves to solve problems non-mapped in their logic, according to the remote environment characteristics. Also, they can exhibit an evolutionary intelligence that allows them to enrich its decision process with the obtained data as they travel through the net (when they visit each enterprise of the cluster). For example, if an VE modifies its formation "on the fly", i.e. if some enterprises are replaced by others, the mobile agents simply migrate to new partner enterprises. This means that they will follow a new route, with dynamic, flexible and intelligently readapted missions, without changing the control architecture. Nevertheless, these MAg properties bring some intrinsic problems, such as the complexity of their programming and security policies to be established.

\section{THE MOBIC ARCHITECTURE}

The MobiC system has a hybrid and semi-hierarchical architecture. The system is composed of stationary and mobile agents. The types ("classes") of agents needed in a system are a consequence of an analysis of several parameters (Malone, 88), that attempted to ally functional flexibility with good performance. Another aspect is that the solution involves an interaction with the human supervisor of each enterprise in order to obtain the mould's price - an extremely critical information in this industry sector. It is one facet of the non-automatic solution/system.

For the TECHMOLDES scenario, three different classes of agents were created:

- Broker (Br): stationary agent that acts as the system global supervisor, and as an interface with the human broker. It is responsible for MAg creation. 
- Agent Enterprise (AE): stationary agent that represents each enterprise.

- Mobile Agent Consortium (MAg): it is the agent that makes the "connection" among the two physical entities of the system: the broker and the enterprises. It is the agent that will be sent to each TECHMOLDES enterprise to execute a certain mission, basically defined as "search of information".

Aiming at creating a VE for a given business, the broker creates the MAg, which moves to the (pre-selected) enterprises of the cluster, searching for information. The MAg is then transferred to the first enterprise, thus having a mission to be fulfilled. This requires that the MAg knows the location of each enterprise which it intends to migrate. CORBA Name Service supplies this "address" giving the reference of the respective DMP (Distributed Manager Process), an auxiliary process that acts as the enterprise's firewalls from the MobiC point of view. Through the CORBA interface and, once authorized, the $\mathrm{MAg}$ communicates with the stationary agent that represents the enterprise (EA), asking to the desired information. The EA looks for the information in the enterprise's local database (that is fed by the PPC) and gives the information to the MAg.

When the MAg has all the necessary information of every enterprise and before leaving for another enterprise, it comes to the enterprise user supervisor, shows the information that it has obtained and asks him for a final approval. The MAg leaves the enterprise with the required information, moving to the next enterprise. When it leaves, a log file is recorded, describing the operations done by the $\mathrm{MAg}$ and the date and hour that they have occurred. This procedure is repeated until all the candidate enterprises have been visited. Once possessing all the information, the MAg comes back to the broker's computer and generates the possible VEs. When the computation is finished, a graphical interface of the broker environment is exhibited (Figure 3). Each coalition represents a VE and its scheduling. Currently, the scheduling are generated both in backward and forward, based on the planned start and end production dates of each mould from the involved enterprises.

At last, the human broker evaluates the scheduling quality of each alternative and, with the enterprises' representatives, chooses the most appropriate coalition and sends the final offer to the client. The MAg, having finished its mission, is eliminated by the system automatically.

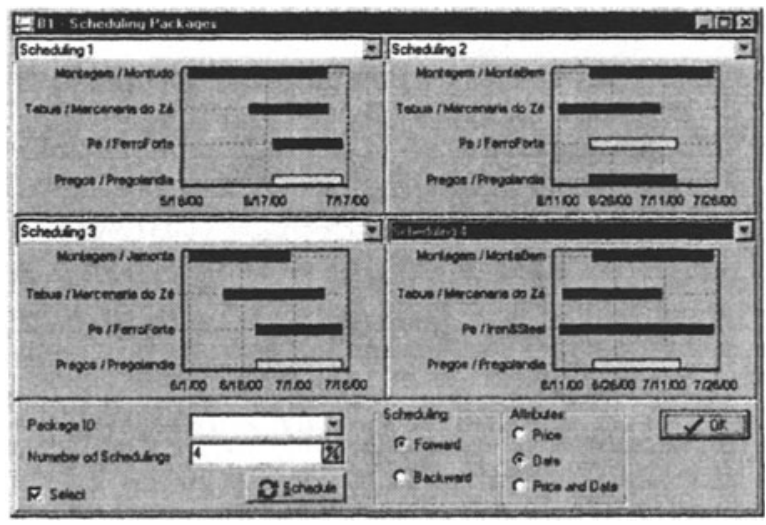

Figure 3 - VE alternative schedules 
It is important to state that several possible schedules are usually generated. The system allows to "ordinate" the best alternatives based on delivery times and/or lowest prices.

\section{IMPLEMENTATION}

For the implementation, the computing environment is so far homogeneous, with all the computers using the same platform (PCs / Windows NT). A supporting software, the MASSYVE KIT (MASSYVE), is used for the generation of the infrastructure for the multi-agent system. The system has been coded in $\mathrm{C}++$.

In terms of CORBA, the C++ TAO ORB (TAO) is used. The database is the Interbase (a shareware), and a small object-oriented layer was developed on it. The (very lean) multi-agent high-level protocol is proprietary.

A language for the modeling of the agent's mission has been developed (APDL Agents Plan Definition Language) which is modeled in XML in order to provide a better interoperation support when a dynamic alteration of the remote missions takes place. Figure 4 shows an instance of the developed language (a XML document) for the following agent mission: visit enterprise (looks for the information, interacts with the enterprise supervisor, and moves for the next enterprise), create VES and evaluate VE (accordingly the desired parameters, like price in this example).

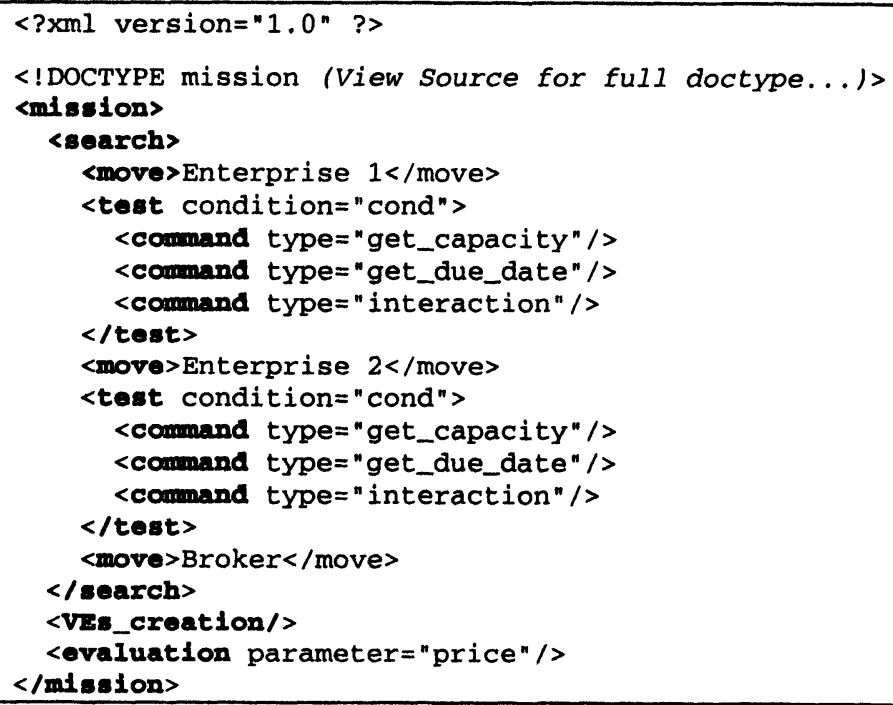

Figure 4 - An agent mission (in XML)

\section{CONCLUSIONS AND NEXT STEPS}

In this paper we have presented a support system to assist a human-broker in the creation of a VE for business opportunities. This work introducing the mobile agents technology for the searching of information within a cluster of enterprises. The mobile agents approach has been considered powerful to support the desired 
advanced management system, offering flexibility and intelligence in the control architecture. It is a very recent paradigm, and therefore there are some open questions to be still discussed, although several of them are intrinsic of mobility and distributed systems.

The aspect of using a homogeneous environment is not seen as a limitation. In practice, this happens very often in this type of enterprises' aggregation, and the utilization of CORBA, that is a standard, encapsulates the existing heterogeneity. Besides, as it is well known, the complete interoperation with Java mobile agents in heterogeneous environment is not as "linear" as it is highlighted.

Next steps include modeling the agent's mission with the capability for dynamic adaptation of plans, as well as to improve the scheduling algorithms. After these steps, the system will be tested by the broker for a more appropriate validation.

In the near future, one intends to add to the system the capacity of supervision of VEs in execution, therefore not just influencing in the creation phase of VEs but also in the support to its operation (Rabelo, 98a).

\subsection{Acknowledgments}

This work has been supported by CNPq - The Brazilian Council for Research and Scientific Development. Thanks to Carlos Gesser and Rui Tramontim for the system implementation.

\section{REFERENCES}

1. Bremer, C., Mundim, A., Siqueira, J., Ortega, L., A Brazilian Case of VE Coordination, in Infrastructures for VE - Networking Industrial Enterprises, Eds. L.M. Camarinha-Matos and H. Afsarmanesh, Kluwer Acadeic Pub., pp.377-386, 1999.

2. Brugali D., Menga G., Galarraga S., Inter-Enterprise Supply Chain Integration via Mobile Agents, Globalization of Manufacturing in the Digital Comm. Era of the 21st Century, Ed. Kluwer, 1999.

3. Camarinha-Matos, L.M.; Afsarmanesh, H., The VE Concept, in Infrastructures for VE - Networking Industrial Enterprises, Eds. L.M. Camarinha-Matos and H.Afsarmanesh Enterp., Kluwer Academics, pp.3-14, 1999.

4. Malone, T., Smith S. Modeling the Performance of Organizational Structures. International journal on Operations Research, Vol. 36, pág. 421-437, 1988.

5. MASSYVE, http://centaurus.dee.fct.unl.pt/ massyve.

6. Molina, A., Flores, M., Caballero, D., VE: A Mexican Case Study, in Intelligent Systems for Manufacturing - Multi-Agent Systems and Virtual Organizations, Eds. L. Camarinha-Matos, H. Afsarmanesh and V. Marik, Kluwer Academic Publishers, pp 159-170, 1988.

7. Papaiannou T., Edwards J., Manufacturing Systems Performance and Agility: Can Mobile Agents Help? Special Ed. of Integrated Computer-Aides Eng.1999.

8. Rabelo R. J., Spinosa L.M., Mobile-agent-based Supervision in Supply Chain Management in the Food Industry, Proceedings AGROSOFT 97, Belo Horizonte, Brazil, 1997.

9. Rabelo R. J., Klen A. P., Spinosa L. M., Ferreira A. C.. Agile Supply-Chain Coord. in the Virutal Enterprise. $4^{\text {th }}$ IFAC/IFSA Brazilian Symposium on Intelligent Automation - SBAI'99, São Paulo, SP, 1998.

10. Rabelo, R. J.; Vallejos, R.V., A Semi-Automated Brokerage for a Virtual Organization of Mould and Die Industries in Brazil, Proceedings IFIP Conference on E-Commerce, E-Business, EGovernment, Zurich, Switzerland, October 2001.

11. Rocha, A., Oliveira E., An Eletronic Market Architecture for hte Formation of VE, in Infrastructures for Virtual Enterprises - Networking Industrial Enterprises, Eds. L.M. Camarinha-Matos and H. Afsarmanesh, Kluwer Acadeic Pub., pp.377-386, 1999.

12. Szirbik, N.B.; Goossenaerts J.B.M., Mobile Agent Support for Tracking Products in VE, Agents for Electronic Commerce and Managing the Internet-Enabled Supply Chain, Seattle, 1999.

13. TAO, http://www.cs.wustl.edu/ schmidv/TAO.html 